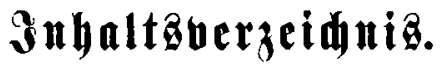

Einleitung.

Geite

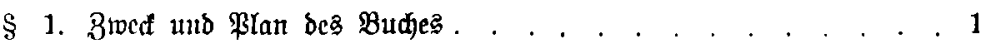

§ 2. Begrünbung deą nactfolgenden ভnffems . . . . . . . . . . . 8

\section{Exites Żitch.}

Gandlungen gegen das Gemeinwejen.

I. Gegen ben æeidjs- uno Staatenorganismus.

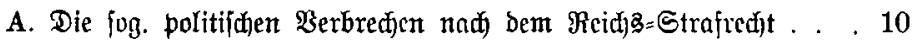

\$ 3. 1. 5odfberrat und \&nndçuerrat . . . . . . . . . . . . 10

§ 4. 2. Belcibigungen bes Lanbeškerrn, ber Fïrjten und Befandten 16

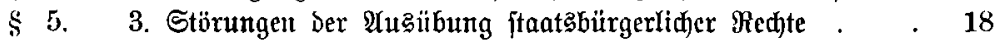

§ 6. 4. Wiscritand gegen bic Staat\&getwalt . . . . . . . . . . . . 19

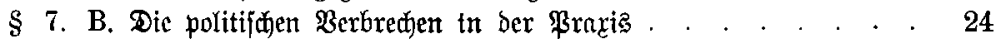

II. Gegen die offentfifie Qronung.

A. Friebensftörungen . . . . . . . . . . . . . . . . . . . 29

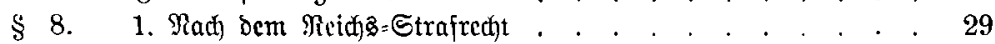

§ 9. 2. Friedensftïruntgen in ber \$raria . . . . . . . . . . . . . . 32

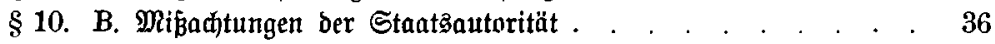

§11. C. Berlekungen der $\mathfrak{B e l}$ rpflicht . . . . . . . . . . . . . . . 41

\section{III. Żerlezungen von Ereue und grauben.}

A. $\Im \mathrm{m}$ Bclbocrtehr . . . . . . . . . , . . . . . . 43

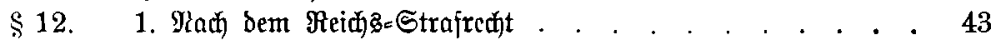

\$ 13. 2. Dic Münzberbrechen in ber Praria. . . . . . . . . . . . 47

B. Urkundenfärfđung und ähnliđc Delifte. . . . . . . . . . 54

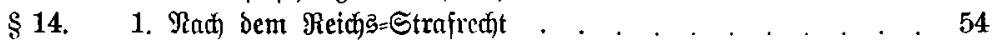

§ 15. 2. Jn ber §rarii . . . . . . . . . . . . . . . . . . 63

\$ 16. C. Falfide Eibesleiftung. . . . . . . . . . . . . . . 72

§ 17. D. Falicie Anfihuldigung . . . . . . . . . . . . . . . . . . . 83

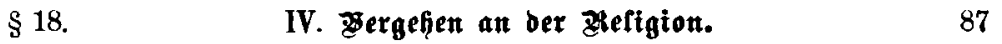


V. Strafbare band (ungen gegen die Sittlidikeif. Seite

§ 19. A. Blutjdande . . . . . . . . . . . . . . . . . . 91

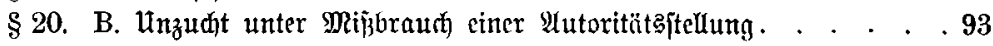

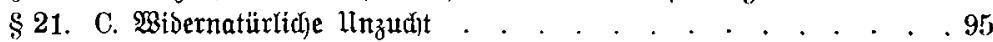

§ 22. D. Unzưt nittcls 3wange . . . . . . . . . . . . . . . . 97

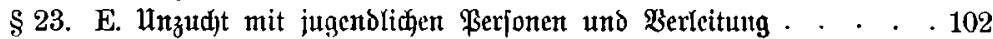

§ 24. F. 凡uppelci . . . . . . . . . . . . . . . . . . 107

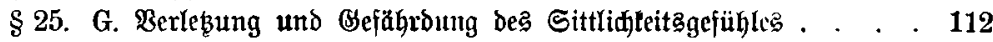

\section{Gemeingefäfirlțłe ftrafbare sand}

§ 26. A. Branditiftuntg

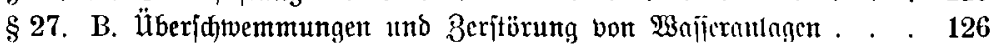

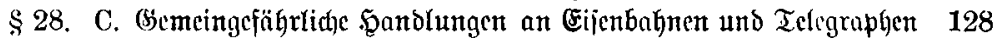

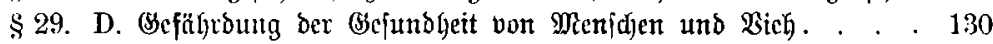

§ 30. E. Die übrigen gcmeingefährłiđłen Şandlungen. . . . . . . 135

\section{Die Antsbefikte.}

\$ 31. A. Im allgemeinen . . . . . . . . . . . . . . . 137

\$32. B. Dic jog. eigentlid)en $\mathfrak{A m t g \delta e l i f t e ~ . ~ . ~ . ~ . ~ . ~ . ~ . ~ . ~ . ~ . ~ . ~} 141$

§33. C. (S)emeine Berbrchen von Bcamten beritbt, fog. uncigentlidje Amtasbelifte .

\section{Bwoeifes Bhutch.}

\section{Gandlungen gegen einzelne Staatsbïrger.}

\section{Gegen Seib und Seben.}

A. Iötung . . . . . . . . . . . . . . . . . . . . 149

§34. 1. Rach dent Reid) $=$ Strajredft . . . . . . . . . . . 149

§ 35. 2. \$n ber \$rarie . . . . . . . . . . . . . . . . 156

§ 36. B. Uftreibung ber Leibesfrudft . . . . . . . . . . . . . 167

C. Rörperberlebungen . . . . . . . . . . . . . . . 173

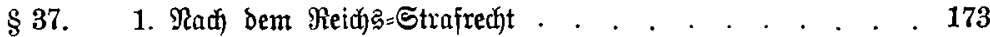

§ 38. 2. Эn ber łraxiă . . . . . . . . . . . . . . . . . . 180

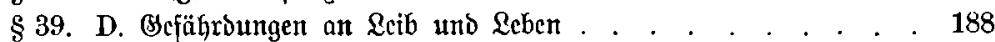

II. Gegen ben zerfonenftand unb Eherenite.

§ 40. A. Berlebungen bes ßerjonenitantb . . . . . . . . . . 194

§ 41. B. Berleğungen bon (E)eredten . . . . . . . . . . . . . . . . 197

\section{Gegen bie perfontidie Greif̧eit.}

§ 42. A. Freiheităberaubungen . . , . . . . . . . . . . . 200

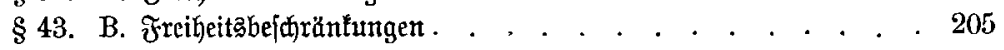

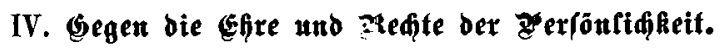

§ 44. A. Ehrbcrlebunger . . . . . . . . . . . . . . . . 211

\$ 45. B. Berlebeungen anberer Biechte i.er ßerjönlidfeeit . . . . . . 225 
V. Gegen bas \$ermógen. Seite

A. Der Diebjtabl . . . . . . . . . . . . . . . . 230

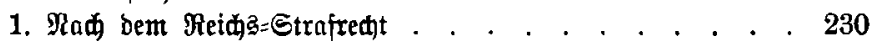

$\S 46$. a. $\mathfrak{3} \mathfrak{m}$ allgemeinen . . . . . . . . . . . . . . . 230

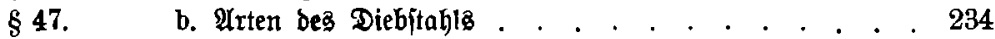

§48. a. $\mathfrak{\Im m}$ allgemeinen . . . . . . . . . . . . . . 244

b. Eirzelne Diebjtahlsarten . . . . . . . . . . . 250

\$ 49. a. Der eimfadie Diebjtafl. . . . . . . . . . . 250

$\S 50$. B. Sajmere Diebjtäble . . . . . . . . . . . . 260

§ 51. B. Die Unteriळlagung . . . . . . . . . . . . . . . . 272

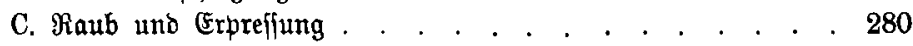

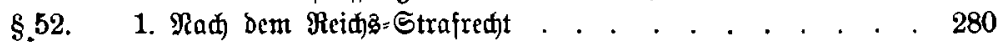

§53. 2. Jn ber \$rarcis . . . . . . . . . . . . . . . . . . . 290

D. Begünftigung un๖ Đehlerei . . . . . . . . . . . . 296

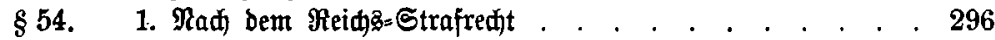

§ 55. 2. Jn ber Praxia . . . . . . . . . . . . . . . . . 301

E. Betrug . . . . . . . . . . . . . . . . . . . 308

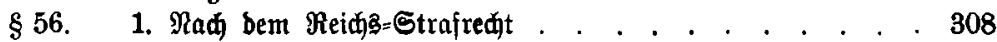

§ 57. 2. In Der ßrarcī . . . . . . . . . . . . . . . . . 315

§ 58. F. Untrcue und äbnlide ftrafbare ந̨anblungen. . . . . . . 327

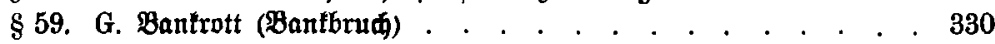

\$60. H. Strafbarer Eigennut. . . . . . . . . . . . . . 332

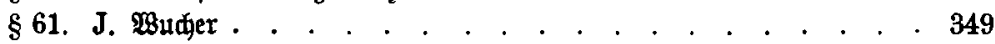

§ 62. K. Sa孔bejđäbigung. . . . . . . . . . . . . . . . 352

\section{Ḋnhang.}

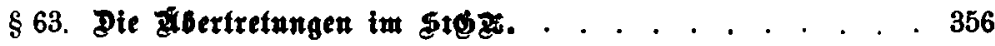

\$64. \$trafbate sandrungen in anberen Zetosgefę̧en . . . . 367

Alphabetifąes und Zaxagraphen-Ziegifter. 